\title{
CLINICAL PROFILE AND SHORT-TERM OUTCOME OF ACUTE NEPHRITIC SYNDROME IN CHILDREN
}

\author{
Surya Kandashamparambil Kamalakarababu1, Ansu Sam², Sajini Varghese ${ }^{3}$
}

${ }^{1}$ Assistant Professor, Department of Paediatrics, Government Medical College, Kottayam.

${ }^{2}$ Senior Resident, Department of Paediatrics, Government Medical College, Kottayam.

${ }^{3}$ Assistant Professor, Department of Paediatrics, Government Medical College, Kottayam.

\section{ABSTRACT}

\section{BACKGROUND}

Glomerulonephritis generally presents as a constellation of findings that includes haematuria, proteinuria and oedema. Poststreptococcal glomerulonephritis is the commonest form of acute glomerulonephritis in developing countries.

\section{Objectives-}

1. To study the clinical profile of acute glomerulonephritis.

2. To study the different clinical laboratory parameters at admission and at 8 weeks of onset of illness.

\section{MATERIAL AND METHODS}

This is a prospective, descriptive study conducted in a tertiary care teaching hospital in South India from January 2016-December 2016. Data regarding the clinical features, laboratory parameters, treatment were collected. All these patients were further followed up at 8 weeks and descriptive analysis done.

\section{RESULTS}

The most common cause of glomerulonephritis in the study group was poststreptococcal glomerulonephritis (42.9\%) followed by drug-induced nephropathy (28.6\%). The most common complaints were haematuria, facial puffiness, decreased urine output and oedema. Hypertension was found only in $14.3 \%$ of study group. $4.8 \%$ of patients had nephrotic range of proteinuria. The most common infection preceding was Pyoderma (61.5\%) in case of PSGN. High ASO titre was seen commonly with pharyngitis. $45.2 \%$ patients had decreased Serum C3 at diagnosis. All the patients were treated conservatively. At 8 weeks followup, haematuria was persisting in $28.6 \%$ patients. Only 2 patients had persistently low serum C3 and single patient had high creatinine.

\section{CONCLUSION}

Post-streptococcal glomerulonephritis is still the most common cause of glomerulonephritis in children followed by drug-induced nephropathy. The changing epidemiology needs to be followed up regarding the need for NSAID use and guidelines to restrict its use in any form to absolute indications only.

\section{KEYWORDS}

Glomerulonephritis, Acute Poststreptococcal Glomerulonephritis, Clinical Profile.

HOW TO CITE THIS ARTICLE: Kamalakarababu SK, Sam A, Varghese S. Clinical profile and short-term outcome of acute nephritic syndrome in children. J. Evolution Med. Dent. Sci. 2017;6(88):6157-6160, DOI: 10.14260/jemds/2017/1337

\section{BACKGROUND}

Glomerulonephritis generally presents as a constellation of findings that includes haematuria, proteinuria and oedema. Glomerulonephritis is caused by a number of disorders that are characterised by glomerular injury accompanied by inflammation. In some cases, it may progress to renal failure.

The classic nephritic syndrome presentation is that seen with acute poststreptococcal glomerulonephritis (PSGN). It is the commonest form of acute glomerulonephritis in developing countries which results from immunological events triggered by many infective agents. (1) Of the estimated 470,000 new annual cases of PSGN worldwide, 97\% occur in the regions with poor socioeconomic status with an annual

'Financial or Other Competing Interest': None.

Submission 22-09-2017, Peer Review 24-10-2017,

Acceptance 30-10-2017, Published 06-11-2017.

Corresponding Author:

Dr. Surya Kandashamparambil Kamalakarababu,

Thushr $(H)$,

Kumaranalloor (P. O),

Kottayam-16.

E-mail: suryamanoj1973@gmail.com

DOI: $10.14260 /$ jemds $/ 2017 / 1337$

(c) (i) $\$$ incidence that ranges from 9.8-28.5 per 10000 individuals.(2.3) In the more developed and industrialised countries, the incidence has continued to decrease.(4)In children, the most common cause of acute glomerulonephritis is poststreptococcal glomerulonephritis.(5) The risk of PSGN is increased in children between 5-12 years of age and uncommon in children less than 3 years of age.(6) PSGN is twice as frequent in males as in females. (7)

PSGN is diagnosed clinically with nephritic picture and evidence of streptococcal infection, decreased serum C3 levels normalising within 8 weeks. There is usually an antecedent history of group A streptococcal infection as either pharyngitis or pyoderma. ${ }^{(8)}$ The clinical presentation varies from asymptomatic, microscopic haematuria to the full blown acute nephritic syndrome.

The clinical features resolve quite rapidly in majority of cases. A diuresis typically begins in one week, and the serum creatinine returns to the previous baseline by three to four weeks. (9) Haematuria resolves usually in three to six months. Proteinuria also falls during recovery, but at a much slower rate.(10) Hypocomplementemia resolves in 8 weeks showing good correlation between clinical resolution with serum C3 levels.(11) 
The longterm prognosis of PSGN has been subject to many studies which shows that these children have a higher incidence of impaired renal function as evidenced by either one or more of the following- elevated serum creatinine, blood urea, albuminuria, haematuria.(12.13) A persistently low C3 level beyond 8 weeks is indicative for renal biopsy. In a developing country like India where there is still a high incidence of PSGN, routine screening of all children with serum C3 is essential. There is a need to follow up all the seemingly benign causes of glomerulonephritis in children.

\section{MATERIALS AND METHODS}

This is a prospective, descriptive study conducted in a tertiary care teaching hospital in South India from January 2016-December 2016. The sample size was taken as 42 as the convenient sample.

The cases admitted fulfilling the criteria for acute nephritic syndrome were included for study after getting informed consent. All cases with pre-existing renal disease were excluded.

Acute Nephritic Syndrome (ANS) is defined as acute onset of haematuria (gross or microscopic), proteinuria in the presence of oedema, hypertension or oliguria.(14)

Acute Poststreptococcal Glomerulonephritis (PSGN): (a) Features of ANS +; (b) Evidence of recent streptococcal infection i.e., pharyngitis, pyoderma or serological evidences (raised ASO); (c) With low serum C3 levels with normalisation at 8 weeks.

IgA Nephropathy: Patients with (a) gross haematuria (b) associated with fever or pharyngitis.

Drug-induced nephropathy: (a) gross/microscopic haematuria (b) presenting after intake of drugs.

ANS otherwise specified: Not amounting to fulfilling the criteria as of above.

Hypertension was defined as systolic and/or diastolic blood Pressure exceeding 95th percentile for age, sex and height.(15) Stage 1 hypertension between 95-99 percentile, stage 2 hypertension more than 99 percentile.

Haematuria is defined as five red blood cells/high power field, in a centrifuged urinary sample. Subnephrotic proteinuria was taken as $1+$ and $2+$ of urine albumin. Nephrotic range of proteinuria is $3+$ or more of urine albumin. Hyponatraemia taken as below $135 \mathrm{mEq} / \mathrm{dL}$, Hyperkalaemia taken as above $5.5 \mathrm{mEq} / \mathrm{dL}$. Serum Creatinine value in age group 2-12 years: $0.3-0.7$ is normal and any value $>0.7$ value is taken as elevated.(16)

High titre of Anti-Streptolysin 0 (ASO) is taken as more than 200 Todd units.(17) Serum C3 was taken as decreased if below $75 \mathrm{mg} / \mathrm{dL}$ estimated by immunoturbidimetric assay. Anaemia defined according to age and sex as mild, moderate and severe anaemia.(18) All the subjects were followed up at 8 weeks and renal function parameters and serum C3 were assessed.

The data entry was done in MS excel and analysed with SPSS version 19. The quantitative data will be analysed as mean and standard deviation whereas the qualitative data as proportion and percentages. The significance of the study will be analysed using chi-square test with significance taken as $p$ less than 0.05 .

\section{RESULTS}

There were 42 cases of glomerulonephritis during the study period of one year. Majority of the children were in the age group of $5-10$ years $(54.8 \%, 23)$ followed by $10-12$ years having $26.2 \%$ (11) and in $2-5$ years $19 \%$ (8). The male to female ratio was found to be $4: 1$. The majority of the cases came under the case definition of PSGN (42.9\%). Others were drug-induced nephropathy (28.6\%), IgA Nephropathy (16.7\%) and Acute Nephritic syndrome otherwise specified.

Majority of the cases of presumed drug-induced nephropathy was caused by Mefenamic acid (58.3\%) followed by Ibuprofen (25\%), diclofenac (8.3\%) and Amoxicillin (8.3\%). Of the study population, $31 \%$ patients had history of infection preceding the illness of which the most common was pyoderma (61.5\%) followed by pharyngitis (38.5\%).

The most common complaints were either cola coloured urine $(23.75 \%)$ or red coloured urine $(27.5 \%)$ followed by facial puffiness (20\%) and decreased urine output (13.75\%), $6.25 \%$ patients also complained of headache. At the time of diagnosis, $14.3 \%$ were hypertensive of which $4.8 \%$ patients had stage 1 hypertension and $9.5 \%$ patients had stage 2 hypertension.

Of the 4 patients with stage 2 hypertension, all required ICU admission, with one patient requiring IV medication for correction of BP, whereas the other three patients required only oral medication. Of the study population, at diagnosis $26.2 \%$ of patients (11) had less than $1 \mathrm{~mL} / \mathrm{kg} / \mathrm{hour}$ ) of urine output, of which oliguria $(<0.5 \mathrm{~mL} / \mathrm{kg} /$ hour$)$ was present in $4.8 \%$ (2) patients only.

$69.1 \%$ of the patients in the study population were anaemic, $54.8 \%$ of the patients had moderate anaemia and $14.3 \%$ had mild anaemia. $23.8 \%$ of patients had hyponatraemia at diagnosis and $16.7 \%$ had hyperkalaemia. In the study population, $45.2 \%$ patients had decreased serum C3 levels at diagnosis. At diagnosis, 66.6\% of patients had subnephrotic range proteinuria (1+ and $2+$ ) and $4.8 \%$ had nephrotic range proteinuria $(3+) .51 \%$ patients had haematuria at diagnosis. Of the patients with infection preceding ANS, $38.5 \%$ of the patients had pharyngitis of which $60 \%$ had increased ASO titre. Of $61.5 \%$ of the patients with infection who had pyoderma, $50 \%$ had increased ASO titre. All patients were treated conservatively.

At 8 weeks followup, $28.6 \%$ had persistent haematuria. None of the patients had proteinuria at 8 weeks followup. $4.8 \%$ (2) patients had hypertension. Only $2.4 \%$ had persistently high creatinine at 8 weeks. At 8 weeks followup of 19 patients with low C3 at diagnosis, only $10.52 \%$ had persistently low values.

\begin{tabular}{|c|c|c|}
\hline Diagnosis & Frequency & Percent \\
\hline PSGN & 18 & $42.9 \%$ \\
\hline Drug-induced nephropathy & 12 & $28.6 \%$ \\
\hline IGA Nephropathy IgA & 7 & $16.7 \%$ \\
\hline A/C nephritic syndrome OS & 5 & $11.9 \%$ \\
\hline Total & $\mathbf{4 2}$ & $\mathbf{1 0 0 . 0 \%}$ \\
\hline Table 1. Distribution of Study Population Based on \\
Diagnosis \\
\hline
\end{tabular}



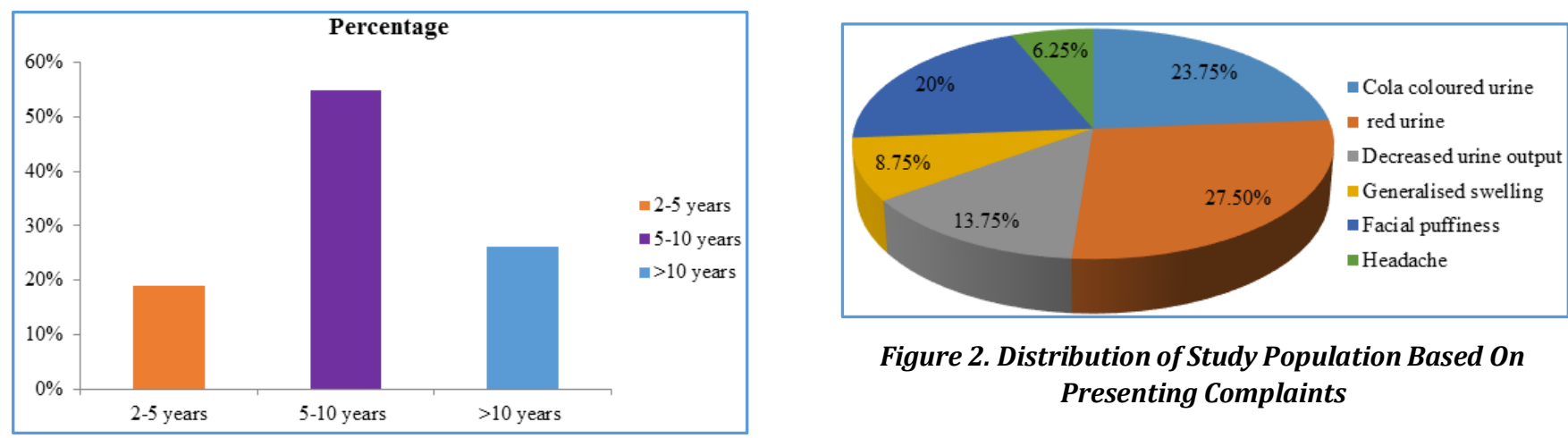

Figure 2. Distribution of Study Population Based On Presenting Complaints

Figure 1. Distribution of Study

Population Based on Age Group

\begin{tabular}{|c|c|c|c|c|c|c|c|}
\hline & BP & $\mathbf{N}$ & Mean & Std. Deviation & T value & P value & Inference \\
\hline \multirow{2}{*}{ Serum Creatinine } & Normal & 36 & 0.732 & 0.2586 & -2.365 & 0.023 & Significant \\
\hline & Hypertensive & 6 & 1.033 & 0.4457 & & & \\
\hline \multirow{2}{*}{ Urine Output } & Normal & 36 & 2.373997 & 1.6982769 & 2.124 & 0.040 & Significant \\
\cline { 2 - 8 } & Hypertensive & 6 & 0.875000 & 0.5521866 & & & \\
\hline
\end{tabular}

\section{DISCUSSION}

In this study, 42 cases were recruited, of which $81 \%$ were male and $19 \%$ were female. The mean age of study population is 7.68 years. The majority of cases came under the case definition of PSGN (42.9\%) followed by druginduced nephropathy in $28.6 \%$ IgA, nephropathy in $16.7 \%$ and Acute nephritic syndrome otherwise specified (ANS OS) (not fulfilling the criteria for the above diagnosis) at $11.9 \%$ cases. Almost $50 \%$ of the cases in the age group of 2-5 years had drug-induced nephropathy, whereas the predominant cause of ANS in 5-10 years was PSGN. In a study done to evaluate the clinical characteristics, complications and outcome of post-infectious glomerulonephritis (PIGN) in children in Southern India, by Gunasekaran K et al, 72 (86.7 \%) had PIGN.(14) Of the 12 cases with drug-induced nephropathy, $92.7 \%$ were caused by analgesics (NSAID) only, $8.3 \%$ were caused by antibiotics (Amoxicillin).

The most common complaints were either cola coloured urine $(23.75 \%)$ or red coloured urine $(27.5 \%)$ followed by facial puffiness (20\%), generalised swelling 8.75\% and decreased urine output (13.75\%), 6.25\% patients also complained of headache. Of the study population $31 \%$ patients had history of infection preceding the illness of which the most common of which was pyoderma (61.5\%), and pharyngitis was $38.5 \%$. Previous studies also show preceding history of skin or throat before poststreptococcal glomerulonephritis.(6)

But in the developing world, PSGN is frequently associated with skin infections, whereas pharyngitis are associated with sporadic PSGN in developed countries.(19) At the time of diagnosis $14.3 \%$ of the patients were hypertensive $4.8 \%{ }^{22}$ patients had stage 1 hypertension and $9.5 \%$ patients had stage 2 hypertension Other studies show that Mild to moderate hypertension occurs in more than $75 \%$ of patients. It is most evident at the onset of nephritis and typically subsides promptly after diuresis in PSGN.(20) In the study conducted by Gunasekharan et al, $21.5 \%$ of children with PSGN developed hypertensive emergency and required sodium nitroprusside intravenous infusion in an intensive care setting.(14) In the index study, all patients with stage 2 hypertension required ICU admission, with one patient requiring IV medication (Labetalol) for correction of $\mathrm{BP}$, whereas the other three patients required only oral medication (Nifedipine, Metoprolol.) At 8 weeks followup, $4.8 \%$ patients had hypertension.

The estimated prevalence of anaemia in developing countries is $39 \%$ in children $<5$ years, $48 \%$ in children $5-14$ years.(21) India is a developing country and in this rural population setting $69.1 \%$ of the patients in the study population were anaemic, $54.8 \%$ of the patients had moderate anaemia and $14.3 \%$ had mild anaemia.

In the index study, $30.9 \%$ patients had elevated ASO. Of the patients with pharyngitis, $60 \%$ had increased ASO titre. Of the patients with pyoderma, $50 \%$ had increased ASO. In the present study, anti-DNase B level was not done due to unavailability of the test. Previous studies showed that if only ASO titre is used to screen for GAS infection, it may be falsely low or negative in patients with skin infections.(22) In the 42 patients with ANS at diagnosis, $45.2 \%$ of patients had abnormal serum creatinine levels. Only $2.4 \%$ patients had persistently high creatinine levels at 8 weeks followup.

Of the study population, at diagnosis, $26.2 \%{ }^{(11)}$ of patients had less than $1 \mathrm{~mL} / \mathrm{kg} /$ hour of urine output, of which oliguria ( $<0.5 \mathrm{~mL} / \mathrm{kg} /$ hour) was present in $4.8 \%{ }^{(2)}$ patients only.

$23.8 \%$ of patients had hyponatraemia at diagnosis. $16.7 \%{ }^{(7)}$ of patients had hyperkalaemia. $100 \%$ of the patients had haematuria at diagnosis but no haematuria at 8 weeks.

White A et al had followed up cases with PSGN for 2-15 years and found to have a persistent haematuria in $21 \%$ of the PSGN group compared with $7 \%$ of the control group.(12)

At diagnosis, $66.6 \%$ of patients had subnephrotic range proteinuria. In our study, $4.8 \%$ patients had nephrotic range proteinuria. No proteinuria detected at 8 weeks followup. Previous studies have shown much slower recovery for proteinuria.(10)

In this study, $45.2 \%$ patients with acute nephritic syndrome had had decreased serum C3 levels. At 8 weeks followup of the 19 patients with low serum C3 at diagnosis, 
only 2 patients had persistently low serum C3 levels. In those patients with persistently low serum C3 levels,(2) $50 \%$ of the patients had elevated serum creatinine levels at 8 weeks followup. Becquet et al (2010) demonstrated in their study that none of the children with PSGN had hypocomplementemia for more than 8 weeks showing a good correlation between clinical progress of the disease with the serum C3 levels.(11) Those patients with low C3 none had hypertension, haematuria or proteinuria at 8 weeks followup.

\section{CONCLUSION}

In children with Acute Nephritic Syndrome, most common cause is PSGN with an increase in incidence of drug-induced nephropathy in younger children. The changing epidemiology needs to be followed up regarding the need for NSAID use and guidelines to restrict its use in any form to absolute indications only. In this study, there was no relation which was statistically demonstrable between serum C3 levels and renal function. The patients with PSGN followed up in the short-term of 8 weeks had good outcome with $50 \%$ cases with persistently decreased low C3 levels (who had elevated serum creatinine). These patients need to be followed up for worsening renal function.

\section{REFERENCES}

[1] Rodriguez-Iturbe B, Mezzano S. Acute post infections glomerulonephritis. In: Avner ED, Harmon WE, Niaudet P, et al. eds. Pediatric nephrology. $6^{\text {th }}$ edn. Berlin Springer 2009:743-55.

[2] Carapetis JR, Steer AC, Mulholland EK, et al. The global burden of group A streptococcal diseases. Lancet Infect Dis 2005;5(11):685-94.

[3] Rodríguez-Iturbe B, Musser JM. The current state of poststreptococcal glomerulonephritis. J Am Soc Nephrpol 2008;19(10):1855-64.

[4] Roy S, Stapleton FB. Changing perspectives in children hospitalised with poststreptococcal acute glomerulonephritis. Pediatr Nephrol 1990;4(6):585-8.

[5] Zhang Y, Shen Y, Feld LG, et al. Changing pattern of glomerular diseases at Beijing Children's hospital. Clin Pediatr (Phila) 1994;33(9):542-7.

[6] Blyth CC, Robertson PW, Rosenberg AR. Poststreptococcal glomerulonephritis in Sidney: a 16year retrospective review. J Paediatr Child Health 2007;43(6):446-50.

[7] Rodriguez-Itrube B. Post infections glomerulonephritis. Am J Kidney Dis 2000;35:445.

[8] Nissenson AR, Baraff LJ, Fine RN, et al. Poststreptococcal acute glomerulonephritis: fact and controversy. Ann Intern Med 1979;91(1):76-86.

[9] Ferrario F, Kourilsky 0, Morel-Maroger L. Acute endocapillary glomerulonephritis in adults: a histologic and clinical comparison between patients with and without acute renal failure. Clin Nephrol 1983;19(1):17-23.
[10] Potter EV, Lipshultz SA, Abidh S, et al. Twelve to seventeen-year follow-up of patients with poststreptococcal glomerulonephritis in Trinidad. $\mathrm{N}$ Engl J Med 1982;307(12):725-9.

[11] Becquet 0 , Pasche J, Gatti $H$, et al. Acute poststreptococcal glomerulonephritis in children of French Polynesia: a 3-year retrospective study. Pediatr Nephrol 2010;25(2):275-80.

[12] White AV, Hoy WE, McCredie DA. Childhood poststreptococcal glomerulonephritis as a risk factor for chronic renal disease in later life. Med J Aust 2001;174(10):492-6.

[13] Hoy WE, White AV, Dowling A, et al. Poststreptococcal glomerulonephritis is a strong risk factor for chronic kidney disease in later life. Kidney Int 2012;81(10):1026-32.

[14] Gunasekaran K, Krishnamurthy S, Mahadevan S, et al. Clinical characteristics and outcome of post-infectious glomerulonephritis in children in Southern India: a prospective study. Indian J Pediatr 2015;82(10):896903.

[15] Blood pressure tables for children and adolescents NHLBI, NIH. 2016. http://www.nhlbi.nih.gov/healthpro/guidelines/curr ent/ hypertension-pediatric-jnc-4/blood-pressuretables.

[16] Andropoulos DB. Appendix B: pediatric normal laboratory values. Gregory's Pediatric anesthesia. Wiley-Blackwell 2012:1300-14 http://onlinelibrary.wiley.com/doi/10. 1002/9781444345186.app2/

[17] Popovic-Rolovic M. Serum C3 levels in acute glomerulonephritis and postnephritic children. Arch Dis Child 1973;48(8):622-6.

[18] World Health Organization. Haemoglobin concentrations for the diagnosis of anaemia and assessment of severity. Vitamin and Mineral Nutrition Information System. Geneva, Switzerland: WHO, 2011.

[19] Thomson PD. Renal problems in black South African children. Pediatr Nephrol 1997;11(4):508-12.

[20] Glassock RJ, Adler SG, Ward HJ, et al. Primary glomerular diseases. In: Brenner BM, Rector FCJ. eds. The kidney. $4^{\text {th }}$ edn. Philadelphia: WB Saunders Company 1991:1182-279.

[21] Alvarez-Uria G, Naik PK, Midde M, et al. Prevalence and severity of anaemia stratified by age and gender in rural India. Article ID 176182, Anemia 2014;2014: p. 5.

[22] Kaplan EL, Anthony BF, Chapman SS, et al. The influence of the site of infection on the immune response to group A streptococci. J Clint Invest 1970;49(7):1405-14. 